\title{
Evaluation of Medication Use and Drug Abuse During Pregnancy in
} Tehran

\author{
Mohammad Kazemian ${ }^{1}$, Minoo Fallahi ${ }^{1}$, Seyed Abolfazl Afjeh ${ }^{1}$, Seyed Hossein Fakhraee ${ }^{1}$ and Sara \\ Sanii ${ }^{1, *}$ \\ ${ }^{1}$ Neonatal Health Research Center, Research Institute for Children Health, Shahid Beheshti University of Medical Sciences, Tehran, Iran \\ "Corresponding author: Neonatal Health Research Center, Research Institute for Children Health, Mofid Children's Hospital, Dr Ali Shariati St., Tehran, Iran. Tel/Fax: \\ +98-2122922828, Email: sanii_sara@yahoo.com
}

Received 2017 January 24; Revised 2018 January 14; Accepted 2018 November 01.

\begin{abstract}
Background: Medication consumption and drug abuse are considered important socio-economic and medicolegal issues all around the world. The significance of the problem is highlighted during pregnancy.

Objectives: We aimed to evaluate the prevalence of medication and drug consumption during pregnancy in Tehran.

Methods: In this descriptive study, we selected several maternity hospitals as the sources of our study population. All women of postpartum period willing to participate in the study were included. We prepared self-designed questionnaires to be filled out by trained personnel while interviewing women face to face. All the data were collected and analyzed by SPSS16 software.

Results: In this study, we evaluated 3279 mothers who delivered in 10 different hospitals in Tehran. The result showed that the most common medications used during pregnancy were iron (85.2\%), folic acid (81.7\%), and calcium (48.2\%). In this population, insulin, levothyroxine, and antihypertensive medications were used in 7.1\%, 5.9\%, and 1.8\% of the mothers, respectively. Overall, $14.5 \%$ of our population used medications for medical conditions during pregnancy. Cigarette smoking, alcohol, and substance abuse before or during pregnancy had a very low prevalence in comparison with other developed countries.

Conclusions: The use of medication during pregnancy increases the risk of several complications. Careful pharmaceutical monitoring during pregnancy and national surveys are recommended for obtaining up-to-date information and making a better decision by policymakers.
\end{abstract}

Keywords: Pregnancy Complications, Socioeconomic Factors, Prenatal Care

\section{Background}

Drug consumption and drug abuse, especially in pregnant mothers, may cause some complications and unwanted problems during and after pregnancy. Statistical information about this subject is very valuable and necessary $(1,2)$. Research in this field is very essential due to the lack of data in our patients and the fact that this information will change with time. In 2012, a study was done in Tehran about maternal and neonatal complications of substance abuse in Iranian pregnant women (3).

\section{Objectives}

We decided to do this study in several hospitals in Tehran. It is very important that all pregnant women be asked about past and current drug history in perinatal visits. Every two years, the Canadian Centre on Substance Abuse (CCSA) produces a new report in substance abuse in
Canada series, with each edition shedding much-needed light on an important drug and alcohol-related issue (4). Pregnancy is a certain period of life; some drugs may be very harmful to the fetus and they must be switched to less harmful ones. In this sensitive period, some mothers are ready to change bad habits because of their adverse effects on the fetus.

\section{Methods}

This is a descriptive study, with the inclusion criteria of all pregnant women delivered in a limited period and the exclusion criteria of mothers unwilling to cooperate with the study.

After the determination of sample size, different hospitals of the city were selected (governmental, private, and charity hospitals). We addressed a heterogenous population in this study. A standard questionnaire based on the 
research topic about drug and drug abuse during pregnancy was prepared and completed by a group of trained personnel during interviews with mothers. The study protocol was approved by the Ethics Committee of Shahid Beheshti University of Medical Sciences and written consent was obtained from the mothers.

The information was extracted and analyzed with SPSS16. We used mean, median, and standard deviation for quantitative variables and frequency and percentage for qualitative variables.

\section{Results}

The study was conducted on 3279 mothers who were admitted to different maternity hospitals of Tehran between September 2014 and February 2015. The hospitals were selected with cluster sampling method; three hospitals were governmental and seven hospitals were privet, non-governmental, charitable hospitals. A total number of 3279 patients were examined including 1041 patients (31.7\%) in government hospitals and 2238 patients (68.3\%) in private hospitals. Cesarean section was done in $71 \%$ (44.3 $94 \%$ ) of cases. The mean weight of newborns was $3109.7 \pm$ 524.5 grams (600-6100 grams). The mean age of the mothers was $28.3 \pm 5.4$ ( 12 - 49 years). About 21 mothers (0.64\%) were single. About 2015 mothers (64.5\%) lived in Tehran city and 770 (23.6\%) were from Tehran's suburb areas. Most mothers (97.5\%) received very good perinatal care by obstetricians $(57.1 \%)$ or midwives $(42.9 \%$ ).

The most widely used medicine by mothers was iron $82.2 \%$, folic acid $81.7 \%$, multivitamins $71.5 \%$, Calcium $48.2 \%$, Omega-3 $2.2 \%$, and other supplements and vitamins $<1 \%$.

Six hundred and seven (18.5\%) mothers during pregnancy had diseases including diabetes mellitus in 234 mothers (7.1\%), hypothyroidism in 112 (3.4\%), hypertension in $58(5.9 \%)$, and other diseases in $58(1.8 \%)$. In addition, $20(0.6 \%)$ needed to have surgeries. The course of the disease was different and included less than one month in 126 mothers (20.8\%), 1 - 3 months in 154 (25.4\%), 3 - 6 months in 95 (15.6\%), 6 - 8 months in 49 (8.1\%), 9 months in 89 (14.7\%), and in 94 mothers (15.4\%), it was unclear. Generally, 484 mothers (14.75\%) used different medicines that are summarized in Table 1. The period of special drug use was less than one month in 90 (18.6\%), $1-3$ months in 66 (13.6\%), 6 - 8 months in 36 (7.4\%), and more than 9 months in 292 $(60.3 \%)$.

\section{Discussion}

We conducted a prospective study in 10 different maternity hospitals in 3279 pregnant mothers. These hospitals were located in different parts of the city and we tried

\begin{tabular}{lc}
\hline Table 1. Distribution of Medicine Consumption in Mothers & \\
\hline Drug Groups & No. $(\%)$ \\
\hline Hormonal & $236(48.76)$ \\
\hline Cardiologic & $103(21.28)$ \\
\hline Antibiotic & $30(6.20)$ \\
\hline Sedative & $28(5.79)$ \\
\hline psychology & $19(3.93)$ \\
\hline Gastroenterology & $19(3.93)$ \\
\hline Corticosteroid & $9(1.85)$ \\
\hline Anticoagulant & $7(1.45)$ \\
\hline Antifungal & $7(1.45)$ \\
\hline Narcotic & $7(1.45)$ \\
\hline Supplement & $7(1.45)$ \\
\hline Others & $12(2.48)$ \\
\hline Total & $484(100)$ \\
\hline
\end{tabular}

to involve a heterogeneous population concerning socioeconomic status.

The average age of mothers was $28 \pm 5.4$ years that show the average childbearing age in this study is a little high. It seems that it requires sociological surveys and appropriate measures by policymakers. The number of single mothers $(21,0.6 \%)$ was relatively low when compared to other countries $(5,6)$. In the US, this trend has been increasing since 40 years ago from $8 \%$ in the 1960 s to $24 \%$ in 2012 (7) and the same trend has reported in European countries.

Maternal education was at a suitable level and most of the mothers received good prenatal care. Iron was the most widely used drug during pregnancy with $85.2 \%$, followed by folic acid, multivitamins, and calcium (81.7\%, $71.5 \%$, and $48.2 \%$, respectively). Most of these drugs were prescribed by physicians and they are routine prenatal care drugs in our country. Omega-3 and vitamin B6 had consumption rates of $2.2 \%$ and $0.9 \%$, respectively, and other vitamins were used with a very low percentage (about 5\%).

The mothers' need for iron doubles during pregnancy and this requirement cannot be met by regular diet $(8,9)$. In a recent study, it was shown that the daily intake of iron supplement could prevent neonatal anemia and low birth weight (10). Harvard study showed even small amounts of iron decrease $12 \%$ risk of anemia and 3\% low-birth-weight $(11,12)$. It is recommended that all pregnant women receive ferrous sulfate supplementation from 16 weeks of pregnancy and continue it until three months after delivery. Other vitamins and minerals are also needed during pregnancy, especially in developing countries and poor socioeconomic conditions. Folic acid can prevent some congen- 
ital anomalies and it must be used even before pregnancy. For unplanned pregnancy, it is recommended to use a daily dose of 400 I.U folic acid and folic acid rich food (13-15). Diabetes mellitus was the most common disease (7.1\%). In a study, the overall incidence of diabetes was $6.7 \%$ that was similar to our study but in over 30-year-old women, it was $8.5 \%$ and in women with a diabetic relative increased to $11.6 \%$. It was also shown that with a combination of risk factors, it increased to 61\% (16-18). The rates of hypothyroidism and hypertension were $5.9 \%$ and $1.8 \%$, respectively. In a study, the prevalence of subclinical hypothyroidism was $5.1 \%$ in the white race (Caucasoid) and $1.7 \%$ in African and Mexican people (19). Hypertension is a major problem during pregnancy and about 2 to $3 \%$ of mothers are afflicted during pregnancy. Overall, $14.5 \%$ of mothers used medicines for specific diseases. The most common drugs were insulin, Levothyroxine, antibiotics, sedatives, neurologic, and gastrointestinal-related drugs. The duration of their use was very different. In $96.6 \%$, consultation with a physician had been done and only $3.4 \%$ were without consultation.

Alcohol consumption may have some unwanted effects on the mother-fetus dyad. It can easily cross the placenta and may be a teratogen. Alcohol may have some bad effects on the brain, heart, and lung. It may cause the fetal alcohol syndrome. Some learning and physical disabilities may be permanent during life. The main side effects occur in the initial weeks of life; therefore, it must be stopped as soon as possible. There is no direct relationship between the amount of consumption and severity of complications but maternal factors like age, race, and genetic and its pattern are responsible. According to a report by the US center of disease control and prevention (CDC), during the years 2006 -2010, alcohol consumption in pregnant women was $6.7 \%(20-28)$.

In our study, the prevalence was $0.6 \%$ in 21 mothers that decreased to 19 during pregnancy. The results indicate the low alcohol consumption in our country that is related to regional and cultural beliefs, but despite the privacy of the questionnaires, it is possible some mothers were not interested to declare it.

A Canadian study showed that $19.4 \%$ of pregnant women used FDA category C, D, or X drugs at least once. It also showed that more drugs were used in women with chronic diseases, lower age, and multiple pregnancies (29).

Cigarette smoking was prevalent in $1.8 \%$ of the mothers before pregnancy and continued in 51 (1.6\%) during pregnancy; more than 50\% used it during pregnancy and in $29 \%$ used more than 10 cigarettes in a day.

It has been proven that 12 to $20 \%$ of smoking mothers during pregnancy may be at risk of falling their babies (3032). Continuation of smoking increases the risk of com- mon cold, cough, and otitis media in the baby (33). Smoking during pregnancy may cause decreased birth weight, preterm labor, and infant death. Passive smoking also endangers the mother and fetus (34-37). Fortunately, in our socio-cultural condition, smoking is less common in women than in men, especially in young girls and childbearing ages.

Different types of illicit drugs were used by 26 pregnant women $(0.8 \%)$. It must be considered that the fetus may have even withdrawal syndrome during pregnancy. Congenital malformation, low birth weight, intrauterine growth retardation, prematurity, and perinatal infections may increase (38). Some mothers may use more than one drug and in a study, it was shown that more than $50 \%$ of the addicted mothers used alcohol and cigarettes simultaneously $(2,39)$.

It is necessary to use some medicines for special illnesses during pregnancy. In our study, 157 mothers (4.8\%) had special diseases even before pregnancy like diabetes, hypothyroidism, hematologic, and cardiologic problems. In this situation, it is very important that we use the minimum dose and the safest drugs for the mother and fetus. In conclusion, the use of medication or drugs during pregnancy increases the risk of several complications. Careful pharmaceutical monitoring during pregnancy, as well as national surveys every two to three years, is recommended for obtaining up-to-date information and making better decisions by our policymakers.

\section{Acknowledgments}

The authors would like to thank the Neonatal Health Research Center (NHRC)'s personnel for their cooperation and support.

\section{Footnotes}

Authors' Contribution: Sara Sanii: Corresponding author and editor; Mohammad Kazemian: The main author; Minoo Fallahi: Cooperating author; Seyed Abolfazl Afjeh: Cooperating author; Seyed Hossein Fakhraee: Cooperating author.

Conflict of Interests: The authors confirm that there is no relevant financial interest or financial conflict.

Ethical Considerations: The study protocol was approved by the Ethics Committee of Shahid Beheshti University of Medical Sciences and written consent was obtained from the mothers.

Funding/Support: This project was not supported by any institute. 


\section{References}

1. Chasnoff IJ, McGourty RF, Bailey GW, Hutchins E, Lightfoot SO, Pawson LL, et al. The 4P's Plus screen for substance use in pregnancy: Clinical application and outcomes.JPerinatol. 2005;25(6):368-74. doi: 10.1038/sj.jp.7211266. [PubMed: 15703775].

2. Ebrahim SH, Gfroerer J. Pregnancy-related substance use in the United States during 1996-1998. Obstet Gynecol. 2003;101(2):374-9. doi: 10.1016/S0029-7844(02)02588-7. [PubMed: 12576263].

3. Saleh Gargari S, Fallahian M, Haghighi L, Hosseinnezhad-Yazdi M, Dashti E, Dolan K. Maternal and neonatal complications of substance abuse in Iranian pregnant women. Acta Med Iran. 2012;50(6):411-6. [PubMed: 22837120].

4. Finnegan L. Licit and illicit drug use during pregnancy: Maternal, neonatal and early childhood consequences. Canada: Canadian Centre on Substance Abuse (CCSA); 2013.

5. González L. The determinants of the prevalence of single mothers: A crosscountry analysis. Germany: Universitat Pompeu Fabra and IZA Bonn; 2005.

6. Blau FD, Kahn LM, Waldfogel J. The impact of welfare benefits on single motherhood and headship of young women evidence from the census. J Hum Resour. 2004;39(2):382-404. doi: 10.2307/3559019.

7. Casey T, Maldonado L. Worst off-single-parent families in the United States. A cross-national comparison of single parenthood in the U.S. And sixteen other high-income countries. United States: Legal Momentum, the Women's Legal Defense and Education Fund; 2012.

8. Bothwell $\mathrm{TH}$. Iron requirements in pregnancy and strategies to meet them. Am J Clin Nutr. 2000;72(1 Suppl):257S-64S. doi: 10.1093/ajcn/72.1.257S. [PubMed: 10871591].

9. Stoltzfus RJ, Dreyfuss ML. Guidelines for the use of iron supplements to prevent and treat iron deficiency anemia. 2. United States of America: Ilsi Press; 1998.

10. Pena-Rosas JP, Viteri FE. Effects and safety of preventive oral iron or iron+folic acid supplementation for women during pregnancy. Cochrane Database Syst Rev. 2009;(4). CD004736. doi: 10.1002/14651858.CD004736.pub3. [PubMed:19821332].

11. Peña-Rosas JP, De-Regil LM, Dowswell T, Viteri FE. Daily oral iron supplementation during pregnancy. Cochrane Database Syst Rev. 2012;12. CD004736. doi: 10.1002/14651858.CD004736.pub4. [PubMed: 23235616].

12. Murphy JF, O'Riordan J, Newcombe RG, Coles EC, Pearson JF. Relation of haemoglobin levels in first and second trimesters to outcome of pregnancy. Lancet. 1986;1(8488):992-5. doi: 10.1016/S01406736(86)91269-9. [PubMed: 2871331].

13. Chaparro C, Lutter C, Camacho-Hubner AV. Essential delivery care practices for maternal and newborn health and nutrition. Washington, DC: Pan American Health Organization; 2012.3 p.

14. Evans MI, Llurba E, Landsberger EJ, O'Brien JE, Harrison HH. Impact of folic acid fortification in the United States: Markedly diminished high maternal serum alpha-fetoprotein values. Obstet Gynecol. 2004;103(3):474-9. doi: 10.1097/01.AOG.0000114984.82549.99. [PubMed: 14990409].

15. Centers for Disease Control and Prevention (CDC). Spina bifida and anencephaly before and after folic acid mandate-United States, 19951996 and 1999-2000. MMWR Morb Mortal Wkly Rep. 2004;53(17):362-5. [PubMed: 15129193].

16. Martin JA, Hamilton BE, Ventura SJ. Births: Final data for 2011. National vital statistics reports. Hyattsville: Centers for Disease Control and Prevention; 2013.

17. Hamilton BE, Martin JA, Ventura SJ. Births: Preliminary data for 2012. National vital statistics reports. Centers for Disease Control and Prevention; 2013.

18. Moses R, Griffiths R, Davis W. Gestational diabetes: Do all women need to be tested? Aust N Z J Obstet Gynaecol. 1995;35(4):387-9. doi: 10.1111/j.1479-828X.1995.tb02148.x. [PubMed: 8717560].

19. Aoki Y, Belin RM, Clickner R, Jeffries R, Phillips L, Mahaffey KR. Serum
TSH and total T4 in the United States population and their association with participant characteristics: National health and nutrition examination survey (NHANES 1999-2002). Thyroid. 2007;17(12):1211-23. doi: 10.1089/thy.2006.0235. [PubMed:18177256].

20. Ethen MK, Ramadhani TA, Scheuerle AE, Canfield MA, Wyszynski DF, Druschel CM, et al. Alcohol consumption by women before and during pregnancy. Matern Child Health J. 2009;13(2):274-85. doi: 10.1007/s10995-008-0328-2. [PubMed: 18317893]. [PubMed Central: PMC6090563].

21. Henderson J, Gray R, Brocklehurst P. Systematic review of effects of low-moderate prenatal alcohol exposure on pregnancy out come. BJOG. 2007;114(3):243-52. doi: 10.1111/j.1471-0528.2006.01163.x. [PubMed: 17233797].

22. Koren G, Nulman I, Chudley AE, Loocke C. Fetal alcohol spectrum disorder. CMAJ. 2003;169(11):1181-5. [PubMed: 14638655]. [PubMed Central: PMC264960].

23. Patra J, Bakker R, Irving H, Jaddoe VW, Malini S, Rehm J. Dose-response relationship between alcohol consumption before and during preg nancy and the risks of low birthweight, preterm birth and small for gestational age (SGA)-a systematic review and meta-analyses. BJOG. 2011;118(12):1411-21. doi: 10.1111/j.1471-0528.2011.03050.x. [PubMed: 21729235]. [PubMed Central: PMC3394156].

24. Falgreen Eriksen HL, Mortensen EL, Kilburn T, Underbjerg M, Bertrand J, Stovring H, et al. The effects of low to moderate prenatal alcohol exposure in early pregnancy on IQ in 5-year-old children. BJOG. 2012;119(10):1191-200. doi: 10.1111/j.1471-0528.2012.03394.x. [PubMed: 22712749]. [PubMed Central: PMC4471997].

25. Underbjerg M, Kesmodel US, Landro NI, Bakketeig L, Grove J, Wimberley $\mathrm{T}$, et al. The effects of low to moderate alcohol consumption and binge drinking in early pregnancy on selective and sustained attention in 5-year-old children. BJOG. 2012;119(10):1211-21. doi: 10.1111/j.14710528.2012.03396.x. [PubMed: 22712829]

26. Kesmodel US, Bertrand J, Stovring H, Skarpness B, Denny $\mathrm{CH}$ Mortensen EL, et al. The effect of different alcohol drinking patterns in early to mid pregnancy on the child's intelligence, attention, and executive function. BJOG. 2012;119(10):1180-90. doi 10.1111/j.1471-0528.2012.03393.x. [PubMed: 22712700]. [PubMed Central: PMC4435537].

27. Bailey BN, Delaney-Black V, Covington CY, Ager J, Janisse J, Hannigan $\mathrm{JH}$, et al. Prenatal exposure to binge drinking and cognitive and behavioral outcomes at age 7 years. Am JObstet Gynecol.2004;191(3):103743. doi: 10.1016/j.ajog.2004.05.048. [PubMed:15467586].

28. Floyd RL, O'Connor MJ, Sokol RJ, Bertrand J, Cordero JF. Recog nition and prevention of fetal alcohol syndrome. Obstet Gynecol. 2005;106(5 Pt 1):1059-64. doi: 10.1097/01.AOG.0000181822.91205.6f. [PubMed: 16260526].

29. Yang T, Walker MC, Krewski D, Yang Q, Nimrod C, Garner P, et al. Maternal characteristics associated with pregnancy exposure to FDA category C, D, and X drugs in a Canadian population. Pharmacoepidemiol Drug Saf. 2008;17(3):270-7. doi: 10.1002/pds.1538. [PubMed: 18181228].

30. Malloy MH, Kleinman JC, Land GH, Schramm WF. The association of maternal smoking with age and cause of infant death. Am JEpidemiol. 1988;128(1):46-55. doi: 10.1093/oxfordjournals.aje.a114957. [PubMed: 3381835].

31. Cnattingius S, Haglund B, Meirik O. Cigarette smoking as risk factor for late fetal and early neonatal death. BMJ.1988;297(6643):258-61. doi: 10.1136/bmj.297.6643.258. [PubMed: 3416144]. [PubMed Central: PMC1833960].

32. Stroud LR, Paster RL, Goodwin MS, Shenassa E, Buka S, Niaura R, et al. Maternal smoking during pregnancy and neonatal behavior: A large-scale community study. Pediatrics. 2009;123(5):e842-8. doi: 10.1542/peds.2008-2084. [PubMed: 19403478]. [PubMed Central: PMC2872509].

33. Leonardi-Bee J, Smyth A, Britton J, Coleman T. Environmental tobacco smoke and fetal health: Systematic review and meta- 
analysis. Arch Dis Child Fetal Neonatal Ed. 2008;93(5):F351-61. doi: 10.1136/adc.2007.133553. [PubMed: 18218658].

34. Ekblad M, Korkeila J, Parkkola R, Lapinleimu H, Haataja L, Lehtonen $\mathrm{L}$, et al. Maternal smoking during pregnancy and regional brain volumes in preterm infants. J Pediatr. 2010;156(2):185-90 e1. doi: 10.1016/j.jpeds.2009.07.061. [PubMed: 19818449].

35. Linnet KM, Wisborg K, Obel C, Secher NJ, Thomsen PH, Agerbo E, et al. Smoking during pregnancy and the risk for hyperkinetic disorder in offspring. Pediatrics. 2005;116(2):462-7. doi: 10.1542/peds.2004-2054. [PubMed: 16061604].

36. Thapar A, Fowler T, Rice F, Scourfield J, van den Bree M, Thomas H, et al. Maternal smoking during pregnancy and attention deficit hyperactivity disorder symptoms in offspring. Am J Psychiatry. 2003;160(11):1985-9. doi: 10.1176/appi.ajp.160.11.1985. [PubMed:
14594745].

37. Stroud LR, Paster RL, Papandonatos GD, Niaura R, Salisbury AL, Battle $C$, et al. Maternal smoking during pregnancy and newborn neurobehavior: Effects at 10 to 27 days. J pediatr. 2009;154(1):10-6. doi: 10.1016/j.jpeds.2008.07.048.

38. Lam SK, To WK, Duthie SJ, Ma HK. Narcotic addiction in pregnancy with adverse maternal and perinatal outcome. Aust N Z J Obstet Gynaecol. 1992;32(3):216-21. doi: 10.1111/j.1479-828X.1992.tb01950.x. [PubMed: 1445130$]$.

39. Centers for disease control and prevention (CDC). Alcohol use and binge drinking among women of childbearing age-United States, 2006-2010. MMWR Morb Mortal Wkly Rep. 2012;61(28):534-8. [PubMed: 22810267]. 